\title{
KNOWLEDGE AND ENTERPRISES IN DEVELOPING COUNTRIES: EVIDENCES FROM CHILE
}

\section{Maria Obeso $^{1 *}$ and Maria Sarabia ${ }^{2}$}

${ }^{1}$ Lecturer, Department of Business Administration, University of Cantabria, Av/ Los Castros, 56, 39005, Santander, Cantabria, SPAIN. Phone: +34.942.20.39.25. E-mail:

maria.obeso@unican.es

${ }^{2}$ Associate Professor, Department of Business Administration, University of Cantabria, Av/ Los Castros, 56, 39005, Santander, Cantabria, SPAIN. E-mail: maria.sarabia@unican.es

*Corresponding author

\section{Acknowledgment}

The authors thank to Ministerio de Ciencia e Innovación (project ECO2010-15455) for partial support of this work. 


\title{
KNOWLEDGE AND ENTERPRISES IN DEVELOPING COUNTRIES: EVIDENCES FROM CHILE
}

\begin{abstract}
Knowledge Management is a fundamental tool in order to obtain competitive advantages in organizations. In this paper we present an interesting study about how enterprises in a developing country like Chile manage their knowledge by using variables linked with three interesting concepts related to knowledge: innovation, learning and knowledge sharing. From this information, six clusters of enterprises and two special cases with different behaviours in Knowledge Management and different results are identified. From this information, some conclusions are extracted: (1) clusters 4 and 5 are the best in Knowledge Management (best results) thus other enterprises should replicate their behaviors (2) the Government of Chile should promote more Knowledge Management in order to improve the country's performance; (3) chemical industry is highlighted like one of the most important one related to knowledge; and finally (4) enterprises with a high investment in knowledge are also enterprises with high results. These results are very interesting in order to understand the knowledge activity in a developing country like Chile.
\end{abstract}

\section{Keywords}

Knowledge Management, Chile, Enterprises, KM strategy, cluster analysis 


\section{KNOWLEDGE AND ENTERPRISES IN DEVELOPING COUNTRIES: EVIDENCES FROM CHILE}

\section{INTRODUCTION}

At present time, Knowledge is considered a key resource for countries and organizations. Specifically Knowledge Management is considered as an essential tool in order to obtain competitive advantages in organizations (Nonaka \& Takeuchi, 1995; Davenport \& Prusak, 1998; Drucker, 1998; Davel \& Snyman, 2007; Ajmal et al., 2010), therefore, the process is important to all Governments, but with special emphasis in developing countries because it is the real key to create value.

However, the intangible character of knowledge linked to the heterogeneity of firms, hinders contributions related to Knowledge Management. In this way, despite the numerous studies which have been undertaken in recent years, there is currently no commonly accepted model by all stakeholders that helps to manage knowledge in enterprises (Choi \& Jong, 2010). Besides this information, a gap in the literature is identified: research in Knowledge Management area is essential in order to support decision making process in organizations by using knowledge and this topic is still under discussion because there is not an agreement about it.

In this context, an interesting analysis is presented showing how enterprises in a developing country with a growing benefit manage their knowledge in order to identify if this process should be replicated in other countries following its example. This is very important because there is not much research on this topic, although it is interesting for Governments, managers and scholars. Besides this information, Chile is selected and a cluster analysis is realized with the aim of comparing different behaviors and identifying their similarities and differences. These results have implications for some stakeholders: First, it is interesting for Chilean enterprises, because it explains what they do and what they should do. Second, the results could help the Chilean Government because the analysis shows how the behavior of its enterprises is. Third, the analysis support the decision making process in other developing countries, both in Governments and enterprises.

The paper is structured as follows: first, a bibliographic review about Knowledge Management is presented, analyzing its importance for enterprises and its relationship with innovation, learning and knowledge sharing. Then the methodology is detailed specifying data collection and sample. In the following section, results are analyzed explaining how Chilean enterprises manage their knowledge. Finally, the conclusion includes the main findings of the research, future research possibilities and limitations.

\section{THEORETICAL FRAMEWORK}

Knowledge Management has been used in enterprises from their very first origins, when artisans, soldiers or scholars shared their experience and the secret of their success to trainees (Hansen et al., 1999; King et al., 2007). It was not until the 1990s, however, that it was recognized as a relevant tool in organizations 
(Obeso et al., 2012). Since that time, its popularity as an excellent management tool has increased rapidly as can be demonstrated by the growing number of research in the area (Edvardsson, 2009).

There are several recognized benefits of Knowledge Management, for example: improving operational efficiency, increasing adaptation capacity in a changing and fast environment, strengthening the organizational culture based on people, and improving relationship capacity between workers, suppliers, customers and other stakeholders (Daedalus Report, 2002). Knowledge is therefore recognized as a key organizational resource (Zyngier and Venkitachalam, 2011) with a strategic value because it cannot be imitated easily by competitors (Zack, 1999). Successful Knowledge Management can be a key element in an organization’s survival (Liao et al., 2008).

Similarly, there is not a commonly accepted definition of Knowledge Management (Hlupic et al., 2002) because it includes different activities such as data collection, analysis, storage, diffusion or use (Lancioni \& Chandran, 2009). There are many well-known definitions such as Hibbard's in 1997, which defines Knowledge Management as a process to captain knowledge presented in people, papers or databases and distribute them in order to obtain an improved performance. Another definition is Kebede's in 2010 which defines Knowledge Management as managing the process and tools linked with knowledge with the aim of taking advantage of its potential and supporting the decision making process by facilitating innovation and creativity within the organization and obtaining a competitive advantage.

Obeso et al., (2012) came up with a review based on Knowledge Management definition and they identify the following actions related to Knowledge Management process: create, identify, acquire, develop, distribute, use, share and accumulate. In turn, these actions could be included in the following three categories: innovation (creating and developing knowledge), learning (identifying and acquiring knowledge) and knowledge sharing (distribution, use, sharing and accumulation knowledge); these categories are explained in the following subsections and they will be used in order to select the variables.

\subsection{Innovation and knowledge}

Innovation is an idea which is perceived as something new (Rogers, 2003) and it is considered an essential output in organizations in order to improve their performance and standing in society, where innovation influences economic and social change (Sorensen \& Stuart, 2000; Amar \& Juneja, 2008). The relationship between innovation and Knowledge Management is seen in the definition of the concept of innovation. For example, the one proposed by Herkema (2003) defines innovation as a knowledge process with the aim of creating new knowledge and developing solutions. Plessis also offers a definition linked with knowledge by defining the concept as "the creation of new knowledge and ideas to facilitate new business outcomes, aimed at improving internal business processes and structures and to create market driven products and services” (2007: p. 21).

However, innovation is not only new knowledge (Romer, 1990) but also includes other situations such as processes, techniques or organizational designs (Dougherty \& Hardy, 1996). Kline and Rosenberg (1987) identified the following innovations: a new product, a new process of production, the substitution 
of a cheaper material, the reorganization to increased efficiency or lower costs or an improvement in instruments or methods of innovating.

In this sense, authors such as Parlby and Taylor (2000) argue that Knowledge Management supports innovation processes, generates ideas and exploits the thinking of an organization. Plessis (2007), moreover, posits that Knowledge Management creates an environment for innovation to take place. Following Amar \& Juneja, the relationship between innovation and knowledge can be seen as analogous to the growth of a plant: "The seed is the tacit knowledge, the fertilizer is the explicit knowledge and the soil is human creativity; all three are essential to get innovation" (2008: p. 299). Miles exposes in his paper that "this phenomenon could be thought of as the revitalization of innovation studies in the face of the knowledge-based economy" (2000: p. 388).

Following Pavitt (1984), companies adopt different behaviors according to the innovation process, identifying supplier dominated firms, production intensive firms and science-based firms. Supplier dominated firms are those enterprises belonging traditional sectors, generally small and a low capacity of innovation. Production intensive firms are linked to enterprises where machines and economies of scale are the most relevant sources for their competitiveness. And, finally, science-based firms are enterprises where R\&D and technology presents the most relevant characteristics from them.

\subsection{Organizational learning}

Some studies identify a relationship between Knowledge Management and Organizational Learning. For example, in a study by Jerez-Gomez et al. (2005), Knowledge Management has a positive influence in organizational learning, and this link was confirmed by Liao and Wu (2010). In this sense, Knowledge Management is a strategic key in order to obtain organizational learning.

Organizations that invest in organizational learning obtain better results related to knowledge creation than others that do not (Boisot, 1998). Organizational learning and Knowledge Management therefore need one another in order to survive (Loermans, 2002). The basic aim of organizational learning is to develop new knowledge and increase knowledge existing in an organization (Pemberton \& Stonehouse, 2000). As Moustaghfir puts forward, "organizational learning mechanisms enable this interconnectivity between knowledge assets and constantly renew and enhance their value" (2009: p. 352).

The relationship between Knowledge Management and organizational learning is also seen in the simple definition of learning: A process to acquire knowledge (Wikstrom \& Norman, 1994). Hubber (1991) defines organizational learning as an organization's capability to self-adapt to the environment, to be flexible and generate actions known as a fast response. The concept of organizational learning could also be defined as the process of obtaining knowledge and developing abilities in employees in order to improve performance (Addleson, 1999).

\subsection{Knowledge Sharing}

Knowledge Sharing between employees is essential in order to be a competitive enterprise (Chow \& Chan, 2008). In this sense, literature shows that knowledge sharing is linked with reductions in 
production costs, reductions in production time, improved team performance, improved innovation activity and increased firm performance (Hansen, 2002; Cummings, 2004; Arthur \& Hungley, 2005; Collins \& Smith, 2006; Mesmer-Magnus \& DeChurch, 2009). Moreover, in difficult situations knowledge sharing can increase the credibility of a firm's commitment by making performance drivers (McEvily et al., 2000).

Knowledge sharing is defined as "the provision of task information and know-how to help others and to collaborate with others to solve problems, develop new ideas or implement policies or procedures (...) and it can occur via written correspondence or face-to-face communications through networking with other experts, of documenting, organizing and capturing knowledge for others" (Wang \& Noe, 2010, p. 117). Knowledge sharing thus includes behaviors linked with acquiring knowledge (Chow \& Chan, 2008). Knowledge sharing is related with knowledge creation, considering knowledge sharing as an antecedent (Nonaka, 1991). In addition, it is linked with the process of transforming individual knowledge into organizational knowledge (Foss et al., 2010). The process can be internal (linked with employees) or external (linked with clients or suppliers) (Renzl, 2008).

\subsection{The case of Chile}

Chile is one of Latin America's fastest growing economies. In the past 20 years the country has registered an annual average per capital growth of around 3.8 per cent. Since 1973 this country has presented a high level of institutional stability applying policies of structural reforms and economic openness (Brida et al., 2011). However, productivity and investment have been decreasing over the last decade. Chile has two challenges: improving its productivity and achieving equal opportunities (World Bank website, 2012). Analysis time, it is considered a developing country (PNUD, 2011) with a GDP per capita of about $\$ 14,413$ USD (Banco Central, 2011) and it is characterized by an unequal distribution of wealth (Naciones Unidas \& Gobierno de Chile, 2011).

Following a study published by the Economic Commission to Latin America and the Caribbean (CEPAL) and the Iberoamerican General Secretariat (SEGIB), sustainability and better income distribution in Latin America is possible by orientating policies to innovation (Cimoli, 2010). However, Latin American countries have not heavily invested in this area and their innovation processes are linked with adaptations rather than scientific discoveries. Moreover these countries have more patents in traditional sectors than in innovative sectors such as Biotechnology and Information Technologies (CEPAL, 2008). Only Chile and Brazil have overcome this low-level investment (Cimoli, 2010). From this information, Chile has been selected. Chile is an interesting case study and its businesses have influenced these results. Therefore, this case study could be an example to other developing countries in the same region where innovation is increasingly becoming more important.

Knowledge is thus presented as a fundamental tool for Chile and this paper analyzes how Chilean enterprises manage their knowledge identifying and comparing different clusters of enterprises. This analysis will demonstrate what cluster of enterprises obtains better results by investing more in knowledge. 


\subsection{Main question}

The previous sections brings to light the significance of manage knowledge suitably in enterprises. Nevertheless there are some problems hindering this management related basically to the intangible character of knowledge (Demarest, 1997) and the heterogeneity of the organizations (Obeso et al., 2012), thus there is not a rule applicable to each case. These problems highlights the need of continue on research in this field in order to achieve an agreement and provide information to support decision making process in enterprises.

In this scenario, an original study about how Chilean enterprises manage their knowledge is presented, answering to a need in the literature derived from the difficulty of manage knowledge in the heterogeneous enterprises and developing countries, especially the case of Chile. In order to justify the originality, a search in the Web of Science database in June 2015 with the following requirements has been realized:

- Years: 1900-2014

- Topic: Knowledge Management

- Words in title: "Chile"

- $\quad$ Research area: Business Economics

- Document: papers

In the search, six documents have been obtained and after a review of abstract, the conclusion is that these are not papers related to the present research in this database, thus the analysis is original. Therefore, with this analysis information about an original question answering a gap in the literature is presented, with the aim of support decision making process linked to knowledge for Governments, enterprises and scholars.

To sum up, with the aim of provide new evidences about the significance of knowledge management and tools in order to manage suitable this intangible in the enterprises, the final question is: How do Chilean enterprises manage their knowledge?

\section{RESEARCH METHODOLOGY}

A descriptive research design was selected for the research in line with the aim of the paper. Data has been collected in Chile by Latin America and Caribbean (LAC) Enterprise Survey, an initiative of the World Bank, between May 2010 and April 2011. This data is more updated at the present time. Following the information about the data, the sample for Chile was selected using stratified random sampling in order to make sure that the final total sample includes establishments from all different sectors and obtains unbiased estimates for different subdivisions of the whole population. 1034 questionnaires are being analyzed, including general information, infrastructure and services, sales and supplies, innovation and degree of competition, land and permits, crime, finance, business development services, businessgovernment relations, labor business environment and performance.

Besides the categories proposed in the previous section (theoretical framework), thirty-three variables have been used to the analysis (see Table 1). The first category, named as description, includes 
variables related to the country. They are important when it comes to answer the question related to describe how the different groups are: are there any similarities between enterprises belonging to the same industry? And between enterprises localized in the same region? Are there any similarities between enterprises with a same size?

The second category is named innovation, and it includes variables related to create something new in the enterprise. Then, a new business is create something new, thus the business idea is the first innovation in the enterprise. Besides this, variables linked to the founder and his/her idea are selected. In addition questions linked to the development of products and services inside the firm are in this category. In this way, variables related to those tools used to promote innovation activity in the enterprise are in the analysis (Internet used to develop new products and services, use programs to support innovation, programs to support innovation financing, prevision programs to support innovation and use programs to increase goods and services).

Following the theoretical framework, the category named as learning has been recognized, where variables related to the experience are identified, including those experience that employees have before their incorporation to the firm (years of experience, employees with secondary school, employees with a degree and most difficult skill to find) and also those experience that the enterprise provides (use programs to offer technical assistance, programs to offer technical assistance financing, prevision programs to offer technical assistance, use programs to increase sales in domestic market, use programs to increase quality of goods/services, use programs to reduce energy consumption, category require more training, uses formal training for employees, uses external training for employees, uses internal training for employees and programs to train financing).

Finally the last category, like in the previous section was identified, is linked to knowledge sharing by the enterprises. In this way, variables linked to programs to make business alliances with suppliers or clients, financing entities and exporting activity are identified.

Then, a cluster analysis where Chilean enterprises are classified depending how they manage their knowledge is realized. Cluster Analysis is a statistics technique based on "classified objects (that is to say respondents, products or other entities) where each object is very similar to others in the same cluster" (Hair et al., 1999, p. 492). Clusters have internal homogeneity and very high external heterogeneity if they are compared to others clusters (Hair et al., 1995). Then, the different behaviors between clusters are compared using a descriptive technique and analyze the more interesting variables linked with Knowledge Management.

[Insert Table 1 about here]

\section{MANAGING KNOWLEDGE IN CHILEAN ENTERPRISES}


Firstly, a hierarchical cluster analysis has been applied using the average linkages between groups method using only knowledge variables. With the results and using the dendrogram obtained, an imaginary line has been drawn on the first quartile and eight clusters of enterprises have been identified (see Table 2).

\subsection{Results: clustering Chilean enterprises}

The first cluster is composed of 756 enterprises with a medium average of sales per employment $(52,926)$. It is composed mainly of enterprises from the food, fabricated metal, retail and chemicals industries (more than 50 per cent) (see Table 2). Studying the size of the enterprises, this cluster is formed by medium and large enterprises (small enterprises are only 28 per cent) (see Table 3). It has a medium average of enterprises investing in knowledge activity: it does not highlight whether it is a high-level or low-level investment (see Table 4). In relation with public support, there is a small percentage of enterprises receiving public financing, not including public support for employee training where 32.5 per cent of enterprises receive funding (see Table 5). And finally, all enterprises in Cluster 1 in which the respondents are also the founders of the firms were selected and their motivations were analyzed (see Table 6). Linked with this point, 33.6 per cent of founders in Cluster 1 found the enterprises developing a new idea and only 30 per cent replicating a business idea by others.

[Insert Table 2 about here]

The second cluster is composed of only 30 firms with low average sales per employee $(35,214)$. It is composed mainly of food, retail (with a special weighting) and fabricated metal industries (50 per cent in total) (see Table 2). In relation with the size of firms, the composition is similar to Cluster 1: it is composed mainly of medium and large enterprises, only 28 per cent are small (see Table 3). Analyzing knowledge variables, Cluster 2 highlights investment in programs linked with innovation, learning and knowledge sharing with a high percentage of enterprises using these programs in comparison with other clusters, with the exception of programs for employee training (see Table 4). Also, in comparison with other clusters, Cluster 2 obtains more public support for their initiatives than others (see Table 5). And finally, when analyzing the origin of the business idea, results show that more than 55 cent of firms were created replicating an idea developed by other people, meaning that the ideas of enterprises in Cluster 2 are not very innovative.

Cluster 3 is composed of 123 enterprises and it is the cluster with the lowest scores (measured with average sales per employee variable) (see Table 2). This result can be explained by the composition of the cluster: more than 55 per cent of firms are small companies and only 12 per cent are large (see Table 3). In relation with the industries, cluster 3 is formed by enterprises from the food (34 per cent), fabricated metal (11.4 per cent) and plastics (9.8 per cent) industries (see Table 2). In relation with knowledge variables, Cluster 3 stands out because it is the cluster with the smallest percentage of enterprises investing in programs linked with knowledge activity (see Table 4) and also by the fact that it 
has received less public support than other clusters (see Table 5). Finally, the origin of the business idea is analyzed, and in this case there is no clear winner with respect to the origin of the idea (see Table 6).

[Insert Table 3 about here]

The fourth cluster is composed of only 28 enterprises, and it has medium to high average sales in comparison with the others clusters (see Table 2). Cluster 4 is composed mainly of medium enterprises (more than 42 per cent), 28.6 per cent being small and 28.6 being large firms (see Table 3). Knowledge activity is important in this cluster, where most enterprises invest in programs linked with innovation (see Table 4) and they also obtain a significant level of public support for these programs in comparison with other clusters (see Table 5). Finally, cluster 4 is the most innovative one because no enterprises have replicated ideas developed by other people.

The fifth cluster is composed of 65 enterprises and they have the most average sales per employment (with the exception of cluster 7 which is a special case) (see Table 2). It is composed mainly of the chemicals (23.1 per cent) and food (15.4 per cent) industries (see Table 2), and it has a high percentage of large enterprises (almost 50 per cent). Like Cluster 4, Cluster 5 pays attention to knowledge activity and firms investing in these programs (see Table 4) and they obtain more public support for their knowledge activity in comparison with the other clusters (see Table 5). Finally, around 50 per cent of enterprises were created based on a new idea and only 16 per cent were created replicating an idea developed by other firms (see Table 6).

[Insert Table 4 about here]

[Insert Table 5 about here]

[Insert Table 6 about here]

Cluster 6 is composed of 28 enterprises where more than 74 per cent of them are small and medium (see Table 3). It is mainly composed of the food and fabricated metal industries (more than 46 per cent) and their results are poor (see Table 2). In relation with knowledge activity, Cluster 6 has a medium investment in programs which promote innovation activity, learning and knowledge sharing (see Table 4), and there are a high number of enterprises in comparison with other clusters obtaining public support for innovation and employee training.

The seventh and eighth clusters represent a special case in the chemical industry because they are both composed of only one enterprise (see Table 2). In the case of cluster 7, Special Case 1, a large enterprise is identified (see Table 3) with the best result measured across sales per employment with a figure about 250.000 (see Table 2). Special Case 1 invests heavily in some programs linked with 
knowledge to offer technical assistance, increase goods and services offered, increase sales in the domestic market, increase quality of goods and services, reduce costs, obtain certificates and training employees (see Table 4), and it obtains public support only for the final program: training employees (see Table 5). Special Case 1 seems to be an old enterprise because the respondent is not the founder and thus there is not information about the business idea (see Table 6).

Finally, Special Case 2 is also composed of a large enterprise in the chemical industry (see Table 3). In this case the results are poorer than in Special Case 1 (see Table 2). However, there are similarities between their Knowledge Management because Special Case 2 invests in knowledge activity: it invests in programs to make business alliances, increasing offered goods, operating in new markets, increasing sales, increasing quality, reducing costs, obtaining a certificate and training employees (see Table 4), and it obtains public support to make business alliances and training employees (see Table 5). In this case, the respondent is the founder, and the business idea was created by modifying an idea encountered in previous occupations by the founder (see Table 6).

\subsection{Discussion}

Eight different behaviors have been identified in order to manage knowledge in Chilean enterprises: six clusters and two special cases. The majority of firms are in Cluster 1 , so this cluster represents the most common behavior managing knowledge. In general, Cluster 1 is represented from all the industries and sizes of firms, and its position is average in relation with the knowledge and innovation (see Tables 4, 5 and 6).

The best results are obtained by cluster 5 and the worst results are obtained by cluster 3 . These clusters are very different in relation to descriptive variables: while cluster 3 is composed mainly of small and medium enterprises and the principal industry is food, cluster 5 is composed of large enterprises and the principal industry is chemicals (see Tables 2 and 3). Consequently, their knowledge behavior is very different: on the one hand, with respect to innovation, the investment in programs to support this activity is more than double in the case of cluster 5 compared with cluster 3 . Cluster 5 also receives more public support than Cluster 3 (see Tables 4 and 5). In addition, Table 6 demonstrates that Cluster 5 is more innovative because 50 per cent of the enterprises were created developing a new idea, while in Cluster 3 this percentage is only around 27 per cent. Regarding learning, the difference is also very clear: the percentage of enterprises investing in this activity is always greater in the case of Cluster 5 in comparison with Cluster 3, and public support is also high (see Tables 4 and 5). Finally, linked with knowledge sharing, the percentage of enterprises in Cluster 5 is more than double in comparison with Cluster 3 (see Tables 4 and 5). With this data, the idea is about there are some enterprises with high investment in knowledge and good results measured across sales by employee, and there are some small enterprises with a poor investment in knowledge with results lower than others. This idea is linked to previous contributions like Kebede (2010) who relates knowledge to competitive advantages in enterprises. 
Cluster 4 represents similar behavior to Cluster 5 linked with knowledge activity. The principal difference is their composition, because Cluster 5 is composed mainly of large enterprises while Cluster 4 is composed mainly of medium-sized firms (see Table 2). The percentage of enterprises investing in knowledge in Cluster 4 is almost always a little lower than in Cluster 5 (see Tables 4 and 5). The results in the case of Cluster 4 are the second best behind cluster 5 (see Table 1), and enterprises formed in Cluster 4 are also innovative because more than 58 per cent of enterprises were created developing a new idea. Thus Cluster 4 is a special cluster that follows closely behind Cluster 5.

From this information, enterprises interested in improving their situation using Knowledge Management should replicate the behavior of Clusters 4 and 5, that is to say, they should invest more resources in knowledge. This is agree with previous contributions explained in the Literature review section, where Zyngier and Venkitachalam (2011) consider knowledge as a key organizational resource, and Liao et al. (2008) identifies this resource as essential in order to achieve survival.

Cluster 2 has similar behavior to Cluster 1 with an intermediate position, however it has some particularities. Firstly, their results are lower than in Cluster 1 although their composition in terms of size of enterprise is very similar. Thus the following question (see Tables 2 and 3) is considered: if the composition is similar, why do enterprises in Cluster 2 obtain worse results than in Cluster 1 ? In the case of Cluster 2, the principal difference is the origin of business idea: more than 44 per cent of enterprises were created replicating an idea developed by other firms thus they are not innovative firms (see Table 6).

In the case of Cluster 6, the results are the second worst. This difference can be explained with knowledge investment, because although it has a medium-level of investment in knowledge activity, in the case of knowledge sharing it is less than in the other clusters (see Table 4), and these enterprises do not receive public support for this part of Knowledge Management (see Table 5).

In addition, in line with the contributions of Cimali (2010), who recognized a positive relationship between innovative politics and the sustainability in America Latina identifying Chile and Brazil as the first investors. Results show that clusters' receiving more public founds related to innovation are more innovative and have better results. Therefore knowledge has a positive influence in the growing of countries. In this way the Government of Chile should promote knowledge in the clusters, focusing their efforts in those where knowledge is not the key.

Therefore, Cluster 5 is presented as the best cluster with the best knowledge activity, followed by Cluster 4. Cluster 1, which represents the majority of firms, is in a medium position. Clusters 2 and 6 have the worst results of all the other clusters and they present some differences in Knowledge Management: Cluster 2 is composed of non-innovative firms and Cluster 6 does not invest in knowledge sharing in comparison with the others. Finally, Cluster 3 has the worst results and the lowest investment in Knowledge Management.

As a final point, two special cases have been identified and both of them are in the Chemical industry. Special Case 1 is a large and old firm with excellent results. This enterprise focuses its efforts in learning, ignoring knowledge sharing and innovation. This strange situation can be explained by the fact 
that it is an enterprise with a probable long history (the respondent is not the founder) and with sufficient internal resources to obtain good results in terms of knowledge. This special case, where enterprise has a big experience, is according to the statement formulated by Nonaka and Takeuchi (1995: 8) "the most interesting learning come from the direct experience". This firm could be considered as a learning organization, defined as an organization which follows the principles of organizational learning, that is to say, these firms pay attention to the knowledge process and try to develop capabilities in their employees in order to increase their effectiveness (Kim, 1998).

Special Case 2 is also a large firm but in this case the respondent is the founder. Thus it is in its first generation; a new enterprise. This point could explain the lower results in comparison with other enterprises, having only 26,666 million by employee. This enterprise invests homogeneously in all parts of knowledge.

Briefly, the study has demonstrated, once more, the significance of Knowledge Management, which is not a tool more, but it's the key for enterprises and governments. This idea is agreed on previous contributions like Nonaka and Takeuchi's viewpoint (1995), who analyzed Japanese companies. Chile bets on innovation and knowledge, and this investment is being rewarded. And those Chilean enterprises including Knowledge Management as a normal process in their firm have good results.

\section{CONCLUSION}

Starting from Chilean enterprise data, a cluster analysis has been proposed in order to know how these enterprises manage their knowledge. Results show that clusters 4 and 5 are the best in Knowledge Management (best results) so other enterprises should replicate their behaviors, and they also obtain the better general results. In addition, enterprises from non-innovative clusters are obtaining lower results. This is in line with the literature in Knowledge Management area, and it highlights the relevance of Knowledge Management process influencing the enterprise's performance.

Thus the main academic contribution is that, in a field as heterogeneous as the enterprise, the study contributes to the theory showing evidences about highlighting Knowledge Management. In this way discussion includes the relationship between results obtained and previous works in the knowledge management area.

Moreover this study has some managerial implications; on one hand, a very interesting result related to Government's investment is identified: those enterprises which are receiving public funds for innovation and creating knowledge obtain better results (both general and specific of Knowledge Management) than others who are receiving less public funds. This highlights the influence of the Governments in the enterprises, and the situation of enterprises has a direct relationship with countries' health.

In addition, other very interesting result is related to Government's investment. Those enterprises which are receiving public funds for innovation and creating knowledge obtain better results (both general and specific of Knowledge Management) than others who are receiving less public funds. This 
highlights the influence of the Governments in the enterprises, and the situation of enterprises has a direct relationship with countries' health.

These results are very interesting because, once more, Knowledge Management highlight has been demonstrated. It may be obvious, but these evidences are necessary in order to persuade enterprises about including Knowledge Management process as something essential. The study shows there are a lot of enterprises where knowledge is not relevant yet. And the firms need to know results like we present.

Besides this, the main contribution for scholars and the academic area is clear: this study remarks Knowledge Management highlights for enterprises and Governments using an example that had not been used previously: Chile. Because of the heterogeneity of the enterprises, different studies explaining the same (Knowledge Management highlight) are important. In addition, the study exposes the role of the Governments in this process in enterprises.

In the same way, this paper is interesting for Chilean Government, because it shows the situation of enterprises in this country. Thanks to this paper Chilean Government knows that their public funds related to innovation are used by enterprises with good results of Knowledge Management and also in general. Consequently, the Government also knows that there are some enterprises that still need more motivation on the topic. In short, Chilean Government knows that its efforts are been rewarded but they still need motivating Knowledge Management process in enterprises.

Finally this paper is interesting for other countries, especially for those of the same region (Latin America) because they have characteristics in common with Chile; therefore for them the study could be a reflection about it could be them if they invest more in Knowledge Management. They know that Chilean progress is a fact, and investment in Knowledge Management could be one of its secrets. The same reason is applicable to the enterprises; they could be an example in innovative Chilean firms.

Linked to Special Case 1, some future lines of research are identified. In this way, it could be very interesting to analyze this enterprise's internal organization in order to identify where the investment in learning activity is best utilized. In addition, this study could be replicated in other developing countries in the future and compared with this study in order to see the differences between them because it could help governments to orientate their enterprises' knowledge activities.

The study has some limitations. Firstly, related to knowledge sharing, there are no variables in the questionnaire used linked to share knowledge with clients and suppliers. Secondly, the analysis is static because the information is only about the recollected information up only once between 2010 and 2011. Finally, it has the limitations derived from the data collection by The World Bank.

\section{Conflict of Interest}

The authors declare that they have no conflict of interest. 


\section{REFERENCES}

Addleson, M. (1999) What is a good organization?: Learning organizations, community and the rhetoric of the 'Bottom Line'. European Journal of Work and Organizational Psychology, 9(2), 233-252.

Ajmal, M., Helo, P., \& Kekäle, T. (2010) Critical factors for Knowledge Management in project business. Journal of Knowledge Management, 14(1), 156-168.

Amar, A.D., \& Juneja, J.A. (2008) A descriptive model of innovation and creativity in organizations: A synthesis of research and practice. Knowledge Management Research \& Practice, 6(4), 298-311.

Arthur, J.B., \& Hungley, C.L. (2005) Ramping up the organizational learning curve: Assessing the impact of deliberate learning on organizational performance under gain sharing. Academy of Management Journal, 48(6), 1159-1170.

Banco Central de Chile (2011) Indicadores macroeconómicos al cuarto trimestre del 2011. http://www.bcentral.cl/publicaciones/estadisticas/informacion-integrada/pdf/im_cuarto2011.pdf. Accesed 12 November 2012.

Boisot, M.H. (1998) Knowledge assets: Securing competitive advantage in the information economy. New York: Oxford University Press.

Brida, J.G., London, S., Punzo, L., \& Risso, W.A. (2011) An alternative view of the convergence issue of growth empirics. Growth and Change, 42(3), 320-350.

CEPAL (Comision Economica para America Latina y el Caribe) (2008) Espacios iberoamericanos: La economía del conocimiento. Working paper CEPAL/SEGIB, Santiago de Chile.

Choi, B., \& Jong, A.M. (2010) Assessing the impact of Knowledge Management strategies announcements on the market value of firms. Information \& Management, 47, 42-52.

Chow, W.S., \& Chan, L.S. (2008) Social network, social trust and shared goals in organizational knowledge sharing. Information \& Management, 45, 458-465.

Cimoli, M. (2010) Innovar para crecer: Desafios y oportunidades para el desarrollo sostenible e inclusivo en Iberoamerica. Comision Economica para America Latina y el Caribe (CEPAL)/ Secretaria General Iberoamericana (SEGIB), Santiago de Chile.

Collins, C.J., \& Smith, K.G. (2006) Knowledge exchange and combination: The role of human resource practices in the performance of high-technology firms. Academy of Management Journal, 46(3), 544560.

Cummings, J.N. (2004) Work groups, structural diversity and knowledge sharing in a global organization. Management Science, 50(3), 352-364. 
Daedalus Report (2002) Gestión del conocimiento. Working paper, http://www.daedalus.com. Accesed 25 August 2010.

Dalkir, K. (2005) Knowledge Management in theory and practice. Burlington: Elsevier ButterworthHeinemann.

Davel R, \&Snyman, M.M.M. (2007) Influence of corporate culture on the use of Knowledge Management techniques and technologies. South African Journal of Information Management, http://www.sajim.co.za/index.php/SAJIM/article/download/259/250. Accesed 27 February 2010.

Davenport, T.H., \& Prusak, L. (1998) Working knowledge. Boston: Harvard Business School Press.

Demarest, M. (1997) Understanding knowledge management, Long Range Planning, 30(3), 374-384.

Dougherty, D., \& Hardy, C. (1996) Sustained product innovation in large, mature organizations: overcoming innovation-to-organization problems. Academy of Management Journal, 39(5), 11201153.

Drucker, P.F. (1998) The coming of the new organization. In Harvard business review on Knowledge Management. Cambridge: Harvard Business School Press.

Edvardsson, I.R. (2009) Is Knowledge Management losing ground? Developments among Icelandic SMEs. Knowledge Management Research \& Practice, 7, 91-99.

Foss, N.J., Husted, K., \& Michailova, S. (2010) Governing knowledge sharing in organizations: Levels of analysis, governance mechanisms, and research directions. Journal of Management Studies, 47(3), 455-482.

Gururajan, V., and Fink, D. 2010. Attitudes towards knowledge transfer in an environment to perform. Journal of Knowledge Management, 14(6), 828-840.

Hair, J.F., Anderson, R.E., Tatham, R.L., \& Black, W.C. (1999) Análisis multivariante, 5th edition. Madrid: Prentice Hall.

Hair, J.F., Anderson, R.E., Tatham, R.L. , \& Black, W.C. 1995. Multivariate data analysis. Englewood Cliffs, NJ: Prentice Hall.

Hansen, M.T., Nohria, N., \& Tierney, T. (1999) What's your strategy for managing knowledge? Harvard Business Review, 77(2): 106-16.

Hansen, M.T. (2002) Knowledge network: Explaining effective knowledge sharing in multiunit companies. Organization Science, 13(3), 232-248.

Herkema, S. (2003) A complex adaptative perspective on learning within innovation projects. The Learning Organization, 10(6), 340-346. 
Hubber, G. (1991) Organizational learning: The contributing processes and the literatures. Organization Science, 2, 88-115.

Jerez-Gomez, P., Cespedes-Llorente, J., \& Valle-Cabrera, R. (2005) Organizational learning capability: A proposal of measurement. Journal of Business Research, 58(6), 715-725.

Kim, D.H. (1998) The link between individual and organizational learning. In The Strategic Management of Intellectual Capital. Woburn: Butterworth-Heinemann.

King, N., Kruger, C.J., \& Pretorius, J. (2007) Knowledge Management in a multicultural environment: A South African perspective. Aslib Proceedings, 59(3), 285-299.

Kebede, G. (2010) Knowledge Management: An information management perspective. International Journal of Information Science, 30, 416-424.

Kline, S.J., \& Rosenberg, N. (1987) An overview of innovation. In The positive sum strategy, eds. Landau, R., \& Rosenberg, N. Washington, D.C.: National Academy Press.

Lancioni, R.A., Chandran, R. (2009) Managing knowledge in industrial markets: New dimensions and challenges. Industrial Marketing Management, 38(2), 148-151.

Liao, S.-H, \& Wu, C.C. (2010) System perspective of Knowledge Management, organizational learning and organizational innovation. Expert Systems with Applications, 37, 1096-1103.

Liao, S.-H., Fei, W.-C., Liu, C.-T. (2008) Relationships between knowledge inertia, organizational learning and organization innovation. Technovation, 28, 183-195.

Loermans, J. (2002) Synergizing the learning organization and Knowledge Management. Journal of Knowledge Management, 6(3), 285-294.

Martin, B. (2008) Knowledge Management. In C. Blaise (Ed.), Annual review of information science and technology, pp 371-424, Information Today, Inc.: Medford, NJ.

McEvily, S.K., Das, S., \& McCabe, K. (2000) Avoiding competence substitution through knowledge sharing. The Academy of Management Review, 25, 294-312.

Mesmer-Magnus, J.R., \& DeChuch, L.A. (2009) Information sharing and team performance: A metaanalysis. Journal of Applied Psychology, 94, 535-546.

Miles, I. (2000) Services innovation: coming of age in the knowledge-based economy. International Journal of Innovation Management, 4(4), 371-389.

Moustaghfir, K. (2009) How knowledge assets lead to a sustainable competitive advantage: are organizational capabilities a missing link? Knowledge Management Research \& Practice, 7, 339-355. 
Naciones Unidas and Gobierno de Chile. 2011. Objetivos de Desarrollo del Milenio: Tercer Informe del Gobierno de Chile. http://www.pnud.cl/odm/tercerinforme/Tercer\%20Informe\%20Nacional\%20ODM\%20Chile\%202010.pdf. Accesed 6 November 2012]

Nonaka, I. (1991) The knowledge creating company. Harvard Business Review, Nov-Dec, 96-104.

Nonaka, I., \& Takeuchi, H. (1995). The knowledge-creation company: How Japanese companies create the dynamics of innovation. New York: Oxford University Press.

Obeso, M., Sarabia, M., \& Sarabia, J.M. (2012) Gestionando conocimiento en las organizaciones. Germany: Editorial Academica Española.

Pavitt, K. (1984) Patterns of technical change: Towards a taxonomy and a theory. Research Policy, 13(6), 343-373.

Pemberton, J.D., \& Stonehouse, G.H. (2000) Organizational learning and knowledge assets - An essential partnership. The Learning Organization, 7(4), 184-194.

Plessis, M. (2007) The role of Knowledge Management in innovation. Journal of Knowledge Management, 11(4), 20-29.

PNUD (2011) Informe sobre Desarrollo Humano 2011 Sociedad y equidad: Un mejor futuro para todos. Madrid: Programa de las Naciones Unidas para el Desarrollo.

Renzl, B. (2008) Trust in management and knowledge sharing: The mediating effects of fear and knowledge documentation. Omega, 36, 206-220.

Rogers, E.M. (2003) Diffusion of innovations. New York: Simon and Schuster.

Romer, P.M. (1990) Endogenous technological change. The journal of Political Economy 98 (2-Part 5: The problem of development: A conference for the study of free enterprise systems), S70-S102.

Rowley, J. (2007) The wisdom hierarchy: Representations of the DIKW hierarchy. Journal of Information Science, 33(2), 163-180.

Sakaiya, T. (1991) The knowledge value revolution or a History of the future. Tokio: Kodansha International.

Sinotte, M. (2004) Exploration of the field of Knowledge Management for the library and information profession. Libri, 54, 190-198.

Sorensen, J.B. \& Stuart, T.E. (2000) Aging, obsolescence, and organizational innovation. Administrative Science Quarterly, 45(1), 81-112. 
Toffler, A. (1990) Powershift: Knowledge, wealth and violence at the edge of the 21st century. Batman Books: New York.

Wang, S., \& Noe, R.A. (2010) Knowledge sharing: A review and directions for future research. Human Resource Management Review, 20, 115-131.

Wikstrom, S., \& Norman, R. (1994) Knowledge and value: A new perspective on corporate transformation. London: Routledge Press.

Wild R, \& Griggs, K. (2008) A model of information technology opportunities for facilitating the practice World Bank website, http://www.worldbank.org. Accesed 7 November 2012.

Zack, M.H. (1999) Developing a knowledge strategy. California Management Review, 41(3), 125-145.

Zyngier, S., \& Venkitachalam, K. (2011) Knowledge Management governance - A strategic driver. Knowledge Management Research \& Practice, 9, 136-150. 
Table 1. Variables and categories

Category Variables

Description Industry

Size of locality

Size of enterprise

Sales per employee

Innovation Founder

Founder's previous occupation

Business idea

Internet used to develop new products and services

Uses programs to support innovation

Programs to support innovation financing

Prevision programs to support innovation

Uses programs to increase goods and services

Learning Years of experience

Uses programs to offer technical assistance

Programs to offer technical assistance financing

Prevision programs to offer technical assistance

Uses programs to increase sales in domestic market

Uses programs to increase quality of goods/services

Uses programs to reduce unit production costs

Uses programs to reduce energy consumption

Employees with secondary school

Employees with a degree

Most difficult skill to find: social or technical

Category require more training

Uses formal training for employees

Uses external training for employees

Uses internal training for employees

Programs to train financing

Knowledge sharing

Use of programs to make business alliances with suppliers or clients

Programs to make business alliances financing

Prevision programs to make business alliances

Uses programs to open new foreign markets

Uses programs to obtain export certification 
Table 2. Composition of clusters: industries and sales (in percentage)

\begin{tabular}{|c|c|c|c|c|c|c|c|c|}
\hline & Clu_1 & Clu_2 & Clu_3 & Clu_4 & Clu_5 & Clu_6 & Esp_1 & Esp_2 \\
\hline Enterprises & 756 & 30 & 123 & 28 & 65 & 28 & 1 & 1 \\
\hline Sales (in millions) & 52.926 & 35.214 & 18.300 & 59.635 & 174.997 & 33.263 & 250.000 & 26.666 \\
\hline Food & 14,9 & 13,3 & 34,1 & - & 15,4 & 32,1 & - & - \\
\hline Textile & 7,7 & 3,3 & 8,1 & - & 3,1 & - & - & - \\
\hline Garments & 4,8 & 6,7 & 7,3 & - & 1,5 & - & - & - \\
\hline Chemicals & 8,7 & 3,3 & 4,1 & 17,9 & 23,1 & 3,6 & Yes & Yes \\
\hline Plastics & 8,2 & 3,3 & 9,8 & 3,6 & - & 3,6 & - & - \\
\hline Non metallic & 2,8 & - & 3,3 & - & 3,1 & 7,1 & - & - \\
\hline Basic metals & 2,0 & - & - & - & 3,1 & 3,6 & - & - \\
\hline Fabricated metal & 13,9 & 10 & 11,4 & - & 9,2 & 14,3 & - & - \\
\hline Machinery & 2,9 & 6,7 & 0,8 & 3,6 & 1,5 & - & - & - \\
\hline Electronics & 0,4 & - & - & - & - & - & - & - \\
\hline Construction & 0,7 & - & 1,6 & 3,6 & 1,5 & - & - & - \\
\hline Motor vehicles & 0,3 & - & 0,8 & - & - & - & - & - \\
\hline Wholesale & 2,1 & 3,3 & 1,6 & - & 3,1 & - & - & - \\
\hline Retail & 15,6 & 26,7 & 5,7 & 10,7 & 7,7 & 7,1 & - & - \\
\hline Hotel, restaurants & 0,7 & 3,3 & - & - & - & - & - & - \\
\hline Transport & 1,2 & 6,7 & - & - & 1,5 & 3,6 & - & - \\
\hline Others & 11,4 & 6,7 & 10,6 & 3,6 & 9,2 & 21,4 & - & - \\
\hline Don't know & 0,7 & 3,3 & 0,8 & - & - & - & - & - \\
\hline Lost values & 1,2 & 3,4 & - & 57,1 & 16,9 & 3,6 & - & - \\
\hline
\end{tabular}


Table 3. Composition of clusters: size of enterprises (in percentage)

\begin{tabular}{|r|c|c|c|c|c|c|c|c|c|} 
& Clu_1 & Clu_2 & Clu_3 & Clu_4 & Clu_5 & Clu_6 & Esp_1 & Esp_2 \\
\hline Less than 5 & - & - & 0,8 & - & - & - & No & No \\
\hline Small & 28 & 26,7 & 54,5 & 28,6 & 16,9 & 39,3 & No & No \\
\hline Medium & 36,8 & 36,7 & 32,5 & 42,9 & 33,8 & 39,3 & No & No \\
\hline Large & 35,2 & 36,7 & 12,2 & 28,6 & 49,2 & 21,4 & Yes & Yes \\
\hline
\end{tabular}


Table 4. Percentage of enterprises using programs to...

\begin{tabular}{|r|c|c|c|c|c|c|c|c|c|}
\hline & Clu_1 & Clu_2 & Clu_3 & Clu_4 & Clu_5 & Clu_6 & Esp_1 & Esp_2 \\
\hline Make business alliances & 38,9 & 50 & 20,3 & 53,6 & 46,2 & 28,6 & No & Yes \\
\hline Support innovation & 37,4 & 46,7 & 22 & 64,3 & 56,9 & 46,4 & No & No \\
\hline Offer technical assistance & 58,3 & 70 & 32,5 & 75 & 80 & 42,9 & Yes & No \\
\hline Increase goods offered & 44,7 & 50 & 33,3 & 53,6 & 60 & 50 & Yes & Yes \\
\hline Operate in new markets & 14,8 & 13,3 & 7,3 & 14,3 & 18,5 & 21,4 & No & Yes \\
\hline Increase sales & 51,5 & 60 & 35,8 & 75 & 60 & 53,6 & Yes & Yes \\
\hline Increase quality & 63,4 & 56,7 & 43,1 & 85,7 & 78,5 & 64,3 & Yes & Yes \\
\hline Reduce cost & 42,7 & 33,3 & 30,1 & 46,4 & 50,8 & 39,3 & Yes & Yes \\
\hline Reduce energy consump & 24,6 & 23,3 & 19,5 & 25 & 32,3 & 21,4 & No & No \\
\hline Obtain a certificate & 23,5 & 30 & 12,2 & 32,1 & 46,2 & 25 & Yes & Yes \\
\hline Training employees & 61 & 60 & 31,7 & 82,1 & 81,5 & 67,9 & Yes & Yes \\
\hline
\end{tabular}


Table 5. Percentage of enterprises obtaining public support to...

\begin{tabular}{|r|c|c|c|c|c|c|c|c|c|}
\hline & Clu_1 & Clu_2 & Clu_3 & Clu_4 & Clu_5 & Clu_6 & Esp_1 & Esp_2 \\
\hline Make business alliances & 2,9 & 6,7 & 0,8 & 7,1 & 3,1 & - & No & Yes \\
\hline Innovation & 8,6 & 13,3 & 2,4 & 17,9 & 12,3 & 14,3 & No & No \\
\hline Offer technical assistance & 10,2 & 10 & 4,1 & 21,4 & 10,8 & 7,1 & No & No \\
\hline Employee training & 32,5 & 30 & 11,4 & 50 & 35,4 & 42,9 & Yes & Yes \\
\hline
\end{tabular}


Table 6. Business idea (in percentage)

\begin{tabular}{|c|c|c|c|c|c|c|c|c|}
\hline & Clu_1 & Clu_2 & Clu_3 & Clu_4 & Clu_5 & Clu_6 & Esp_1 & Esp_2 \\
\hline Develop a new idea & 33,6 & 11,1 & 27,5 & 58,3 & 50 & 50 & No & No \\
\hline $\begin{array}{r}\text { Modified an idea } \\
\text { encountered in previous } \\
\text { occupations }\end{array}$ & 17 & 22,2 & 18,8 & 41,7 & 11,1 & 10 & No & Yes \\
\hline $\begin{array}{r}\text { Modified an idea } \\
\text { developed by other firms }\end{array}$ & 17,5 & 11,1 & 14,5 & - & 22,2 & 20 & No & No \\
\hline $\begin{array}{r}\text { Replicated an idea } \\
\text { encountered in previous } \\
\text { occupations }\end{array}$ & 13,5 & 11,1 & 11,6 & - & - & 10 & No & No \\
\hline $\begin{array}{r}\text { Replicated an idea } \\
\text { developed by other firms }\end{array}$ & 16,6 & 44,4 & 26,1 & - & 16,7 & 10 & No & No \\
\hline Don't know & 1,3 & - & 1,4 & - & - & - & No & No \\
\hline Lost values & 0,5 & - & - & - & - & - & No & No \\
\hline
\end{tabular}

